\title{
Book Selection in the Reference Department of the New York Public Library
}

As an outgrowth of a committee study of acquisition policies at the New York Public Library, the following was prepared for the readers of College and Research Libraries by the chairman of the committee.

A PRIME MINISTER of Spain once said of his country, "I don't know where we are going, but one thing I do know. Wherever it is, we shall lose our way." Like Spain, a great reference library has many and various provinces, each of which necessarily pursues its way more or less alone. It is, therefore, advisable to pause occasionally and see whether they are all traveling on the same road and in the same direction.

It was probably some such reflection which led to the appointment, in 1943, of a committee to examine the book selection policy followed by the Reference Department of the New York Public Library. To me fell the agreeable post of chairman. The final report of this committee has now been submitted with the unanimous agreement of its members, perhaps with a mental reservation or two. In the details of the report there could be no wide interest, but its general conclusions will perhaps merit the attention of other librarians, showing at least how we regard ourselves.

Early in our investigation it became evident that we are all going in the same direction, though our progress has been retarded at times by side trips along inviting byways. It was generally agreed that the reference department, as a liberally endowed institution possessing rich and, in some instances, unrivaled collections, situated in our largest city, and open to the public with almost no restriction, is unique in this country and must be regarded as one of the few great research libraries of the world.

The ideal objective of such a library is a complete record of human thought, emotion, and action. Its collections should be developed without distinction as to language, date, place, and form of publication. In short, it should have everything. The limitations imposed on us by a practical world should not make us lose sight of this ideal. Our collections should be made as comprehensive as our resources permit, and we should limit them in ways which will do the least injury to their permanent value.

The committee advised a few changes in our current policy. Fiction and poetry have not been emphasized in the past, presumably on the theory that a research library should not provide recreational reading. Rather inconsistently, the dramatic collection has been highly developed. It was the opinion of the committee that imaginative literature should be regarded as one of the most revealing and enduring records of human life and, therefore, as occupying an 
important place in a research library. Not only work currently considered excellent, but the mediocre and bad, should be included as part of the record. We recommended securing at least 75 per cent of current English titles, as well as a representative collection of children's books. (This collection is not for the use of children.) By "English" is meant the work of all writers whose native language is English.

A similar policy was suggested for Russian and Latin American literature because of the current interest in those countries. A representative collection of French and German literature was recommended, together with a selective policy for other countries. By "representative" is meant at least 50 per cent of what is obtainable.

The historical collection, already one of the strongest, should include the local history and genealogy of all countries. The collection of American and foreign newspapers, especially useful in this connection, should be expanded, preferably on microfilm.

Another recommendation was a more liberal policy toward the natural sciences, especially as respects periodicals, which have not been emphasized in recent years.

\section{Central Picture Collection}

The committee discovered a general desire to have a central picture collection, to be formed by consolidating with the present circulation department stock others now maintained by several divisions in the reference department. It recommended such a collection partly for reference and partly for lending. It should be more comprehensive than the present ones.

Chiefs of the subject divisions should be expected to develop comprehensively all the collections in their charge. They should pay special attention to source materials. The first edition of every book wanted should be acquired, if obtainable, and sub- sequent editions which add anything to the first. Facsimiles and reprints of important works are not satisfactory substitutes, though they may be acceptable for current factual material and are preferable for newspapers. As a rule photographic copies of material not in the library should be purchased only when obtainable through a cooperative project. The committee opposed establishment of lists of authors and subjects to be emphasized, believing that division chiefs should have to explain only omissions. But exhaustive collections, meaning everything obtainable by or about a certain author or on a narrowly defined subject, should not be attempted.

All this amounts to a very large order and some ways of modifying it are unavoidable. A research library such as the New York Public Library is necessarily encyclopedic, and the committee was unwilling to recommend the elimination of any subjects. But one basis for curtailing purchases is the purpose for which the book or other publication is intended. Medicine, law, theology, and, in less degree, education, the natural and social sciences, and engineering, provide a vast amount of material useful only in professional training and practice. Much of it is collected by the libraries of professional associations and training schools and some of it is part of the individual's office equipment. It was recommended that material of this kind be secured only in rare instances and for specific reasons. But works on the historical, administrative, and social aspects of these subjects should be comprehensively collected.

Manuals of instruction and practice in every vocation and avocation should be subject to this same general limitation, though not so strictly applied. Care should be taken to avoid duplication. Such books have little permanent value, and for historical purposes a selection is sufficient. 


\section{Limits of Collections}

Another suggested basis for limiting our collections is by division of subject responsibility with other libraries. In respect to manuscripts and very rare books this is probably inevitable. The professional material we have already abandoned to other libraries. Our requirements otherwise are so large that any proposal to limit the collections should be approached with the utmost caution. But neither should we agree to accept responsibility for making exhaustive collections in any subject, since this would compel us to get the professional books, manuals, reprints, and translations, of which we have made a general exception. Even in the event of cooperative agreements it would be unnecessary to acquire all these classes of publications because professional libraries in the city will get them anyway.

The library as we have attempted to describe it in our report is a metropolitan research institution. In my opinion, shared to greater or less degree by members of the committee, supplying visitors with information on the repair of automobiles or preparation of income tax returns is merely one of its incidental functions and one which could be performed better by libraries in which the catalogs and distances are smaller. Our resources should not be dissipated in purchasing material of temporary usefulness, still less in duplicating it.

The ultimate purpose of our collections is to preserve the true record of human life. In Amiel's Journal is an observation pertinent to our work here: "A lively, persistent and disinterested liking for the truth is extraordinarily rare." Yet it is this same liking for the truth, together with the intelligence to recognize it, which is the mark of the educated man. It is our job to provide an instrument for the use of educated men in the hope that eventually we shall have contributed to the development of an educated community.

\section{Evolution at the University of Maryland Libraries}

\section{(Continued from page 12)}

anyway. It is without doubt more flexible and consequently better adapted to handle emergencies caused by illness or resignations. There has been a standardization of procedures, service, and hours, as well as a greater utilization of resources through knowledge of the holdings of the other libraries. The purchase of duplicate expensive items can be controlled by means of centralized ordering.
A final point which appears to merit emphasis is the fact that this is an organization which has come about as the result of guided evolution and not revolution. It was developed in concert and on the basis of mutual agreement rather than by edict on the part of the university administration. Moreover, it contains within itself the seeds for further development without departing from the present basic lines. 